\title{
CONSTITUINTE DE 1987-88: ORGANIZAÇÃO OU INSTITUIÇÃO POLÍTICA?
}

\section{Bruno Bolognesi ${ }^{1}$}

Resumo: As constituintes políticas são usualmente retratadas em dois aspectos: seus procedimentos formais e a conjuntura política e o comportamento dos envolvidos. Porém, até hoje não é possível dizer se a constituinte trata-se de uma organização, de uma manifestação histórica ou se uma instituição em si. A partir do caso da constituinte de brasileira 1987-88 tentaremos expor como a literatura institucionalista pode servir para caracterizar processos constituintes como instituições stricto senso. Fontes essencialmente bibliográficas servirão para um comparativo entre procedimentos, legado e teoria. O objetivo é demonstrar como constituintes podem ser vistas para além de sua organização interna, generalizando conceitos. A conclusão aponta que a constituinte brasileira de 1988 pode ser tomada como uma instituição política.

Palavras-chave: constituintes; instituições; Brasil; constituinte de 1988.

Resumen: Las constituciones políticas que lo forman son generalmente se describe en dos aspectos: los procedimientos formales y la situación política y el comportamiento de los involucrados. Pero hoy no se puede saber si es un componente de la organización de un evento histórico o una institución en sí misma. En el caso de La constituición Brasil 1987-88 y tratar de exponer la literatura institucionalista puede servir para caracterizar los procesos constituyentes y las instituciones en el sentido estricto. Fuentes bibliográficas esencialmente sirven para una comparación entre los procedimientos, el legado y la teoría. El objetivo es demostrar cómo los componentes se pueden ver además de su organización interna, la generalización de conceptos. La conclusión indica que la constitución de 1988 puede tomarse como una institución política.

Palabras-clave: constituciones; instituciones; Brasil; constitucion de 1988.

Abstract: The constituent are usually portrayed in two aspects: its formal procedures and the political situation and the behavior of those involved. But today you can not tell if it is a constituent organization of a historical event or an institution in itself. From the case of a constituent of Brazil 1987-88 we try to expose how the institutionalist literature can serve to characterize constituent processes and institutions in the strict sense. Bibliographical sources essentially serve for a comparison between procedures, legacy and theory. The main goal is to demonstrate how components can be seen in addition to its internal organization, generalizing concepts. The conclusion indicates that the constituent of 1988 may be taken as a political institution.

Key-words: constitutions; institutions; Brasil; 1988's constitution.

\footnotetext{
${ }^{1}$ Doutorando em Ciência Política pela Universidade Federal de São Carlos. Bolsista CNPq.
} 


\section{INTRODUÇÃO}

As discussões que cercam o tema constituinte são usualmente tratadas a partir de pontos de vista ora jornalísticos, ora formalistas. As constituintes brasileiras mais estudadas, 37-38 e 87-88, trazem em si processos de ampla reestruturação no fazer política cotidiano. Talvez por conta disso o radicalismo seletivo dos estudiosos. De um lado a constituinte varguista promoveu uma nova forma de organização do Estado, migrando o Brasil para uma autocracia convicta. Por outro lado, a carta de 1988 tentou figurar termos que deixavam pouca brecha para manobras autoritárias. Deter-nosemos aqui sobre o reacendido debate que cerca a constituinte de 1987-88.

Deste modo, são poucos os estudos que fogem da paixão exacerbada ou do formalismo racionalizado. Como uma proposta alternativa em ver o processo constituinte em si, tentarei elaborar neste artigo alguns traços que escapam ao simples funcionamento interno das comissões e debates e ao mesmo tempo se distancia de posições dotadas de fôlego ideológico. Como então fazer isso, já que o processo em si foi de fato tomado por paixões e ao mesmo tempo por procedimentos rigorosos antes nunca visitados na história política do país?

Nossa alternativa é responder esta pergunta com outra. Será a constituinte brasileira de 1988 dotada de aspectos institucionais? Não se trata aqui de fazer um elogio à formação da Assembléia Nacional Constituinte (ANC), nem mostrar aos senhores que a carta resultante do processo foi importante. Trata-se de colocar a constituinte em si num eixo analítico institucional. A partir das diversas nuances que cercam o conceito de instituição, o objetivo é mensurar em que medida nossa última carta constitucional aproximou-se ou afastou-se dos preceitos institucionalistas.

\section{BREVE REVISÃO BIBLIOGRÁFICA}

Não obstante a teoria das instituições tenha sido abordada em diversas correntes, desde o institucionalismo sociológico, até o de escolha racional, nosso recorte aqui será ao mesmo tempo mais geral e objetivo. Estes termos parecem excludentes entre si, porém cabe aqui utilizá-los apenas para frisar que estamos buscando características mais gerais que cercam instituições. Não se trata de estudar, ou exemplificar teoricamente, as diferentes inclinações que a teoria institucionalista incorreu no curso da história, mas sim de realizar uma tarefa, um experimento teórico.

Não estamos esperando, porém que o enquadramento que fizermos coloque a constituinte de 1988 em absolutamente todos os aspectos regulatórios da teoria institucional. Porém, é salutar notar se alguns desses aspectos foram ali abordados e se 
isso perdurou ao longo do tempo, através de algum efeito da carta constituinte. Ou seja, o elemento permanente que notamos na história política brasileira, não pode ser descartado como aspecto intrínseco do itinerário teórico do institucionalismo clássico. A constituinte é sempre utilizada como arcabouço de democracia e garantia de direitos sociais, civis e políticos. São inúmeros os seguimentos sociais e individuais que utilizam da idéia, do legado, da constituinte como refúgio para suas paixões e objetivos.

Porém, antes de definirmos o que foi a constituinte de 1988, passemos pela sabatina que funda o conceito de instituição em si. Não através de uma reconstituição no tempo ou idiossincrática, mas através de um escopo de analistas. Segundo Rothstein (1998), as instituições devem possuir quatro aspectos centrais: i) criar regulação entre membros com interesses ou características em comum; ii) aplicar tal regulação; iii) julgar a aplicação (ou não) da regulamentação e; iv) punir devidamente os descumpridores da regulação. Ao mesmo tempo em que estes aspectos gerais dão conta de um pool enorme de instituições, eles limitam a existência de instituições que exerçam somente um destes aspectos, não por não serem instituições, mas porque é no limite das instituições que as reconhecemos como tal. Porém, isso parece um problema menor, já que os autores admitem a existência de instituições que cumprem apenas um ou a coexistência de dois ou mais aspectos em uma única instituição.

Nesse momento o leitor poderia inteligentemente questionar sobre que tipo de instituição se trata aqui. Deixo claro que se trata de um tipo somente: instituições políticas. É óbvio que a presunção em analisar a constituinte brasileira de 88 só poderia fazer parte de um rol de autores que trabalham instituições políticas. Assim, não nos custa frisar a relevância da temática como uma área pouco comparada com a prática, deixando para o plano teórico diferenças entre tipos de instituições e suas existências históricas (comprovadas ou não).

Ora, se estamos tratando de instituições políticas especificamente, quais adicionais poderíamos colocar aos critérios acima citados para dar corpo a nosso espantalho? Acredito que duas são suficientes. A primeira é a legitimidade da instituição e dos que ocupam a mesma. Sem isso não é possível que os representados ou membros daquela instituição enxerguem nela alguma fonte liderança e estabilidade. A segunda característica é que a própria instituição possua mecanismos que regulem os conflitos e seja capaz de impor sua vontade sobre setores menos satisfeitos da instituição, ou seja, mecanismos de manutenção de poder institucional, visando a sua permanência e sobrevivência (SUNSTEIN, 1993 e PANEBIANCO, 2005). Com estas duas características penso que o termo política pode ser devidamente colado ao lado do termo instituição. 
Mesmo diante de uma definição apurada como a colocada logo acima, parece importante realizar algumas pequenas considerações sobre o termo instituição. Goodin (1996) assevera a importância que a ciência social deu às instituições sociais ao longo da história. Instituições como a família, a igreja, o rei. Porém a preocupação do "velho institucionalismo" estava em saber como essas instituições funcionavam em torno de si mesmas ou em relação uma com as outras. Goodin alerta que a nova percepção que cerca o tema criou um avanço não em torno do objeto, mas sim na abordagem. Agora interessa aos pesquisadores saber como as instituições afetam o comportamento dos indivíduos (ibidem, p. o5).

Essa nova abordagem sobre instituições parece remeter ao comportamento de indivíduos num dado período de tempo, sobre a égide de mesmas regras e normas estabelecidas, que sirvam de alicerce para a estratégia dos indivíduos. Porém, longe disso outros autores deixaram mais clara sua percepção sobre a forma com que tais estruturas afetam comportamentos e dedicaram-se a explorar o modus operandi destas. Assim, podemos proceder com as constituintes, tentando objetivar alguns traços institucionais que denunciem inclinações mais ou menos próximas da definição de instituição política acima.

De saída poderíamos lançar mão de teorias que valorizam os aspectos históricos que permeiam instituições. A formação de instituições leva em conta arranjos que partem de situações históricas específicas e a disputa dos agentes em torno do controle de recursos. Segundo North (1990), tal disputa e arranjo ao longo do tempo acaba por organizar a distribuição com diferentes pesos nos "modelos mentais" dos atores e gera instabilidade. Apenas com a criação de disposições duráveis e a conseqüente perda de liberdade de manobra, é que podemos entender o modo como os indivíduos preferem perder liberdade em troca de estabilidade (SKOCPOL, 1985).

No bojo deste aparato teórico, a constituinte brasileira de 1988 surge como um exemplo histórico de indivíduos que possuíam interesses em comum, desfrutavam de legitimidade e dispunham de organização interna (isso será detalhado na terceira parte deste artigo). Ainda, a constituinte possuía caráter de soberania estatal. Num determinado sentido específico, o de representar a unidade de um "povo" democraticamente (MACEDO JR., 1997, p. 131).

Como bem coloca Souza e Lamounier (1989), a nova Constituição Brasileira é usualmente analisada como "pactos políticos modelados por forças históricas poderosas", (p. 81). A sugestão é que a força dos agentes e o peso da conjuntura histórica sejam muito maiores do que aspectos institucionais das constituintes. Mesmo a possibilidade teórica em agregar análise ao tema da constituinte se torna uma tentativa de retirar a pecha casuística do tema. Ou seja, colocar apenas os aspectos 
históricos teria por de trás a intenção de retirar do desenho institucional, características fundamentais para o funcionamento regular de uma constituinte.

North (1996) denota em sua conclusão sobre a dependência do passado que todas as instituições prescindem e que, muitas vezes, são deixadas de lado pelos analistas. Porém a literatura não dá conta, a não ser historiograficamente, de remontar os processos de formação institucional da constituinte de 1988. Apenas lembra que o caráter transitivo, saída de um regime ditatorial em busca de uma democracia, tornou essa constituinte um marco para o exame de processos e de conflitos de interesses dispostos em diferentes pólos ideológicos. O momento de transição criou uma organização baseada em temas que dividiram a constituinte e propiciou aos legisladores formas diferentes de organizarem-se de acordo com disposições partidárias e ideológicas diferenciada. A sugestão organizativa permitiu não somente a análise formal, mas a perpetuação de um legado de disposições política que caracterizam a constituinte como um ancoradouro institucional, onde invariavelmente diferentes agentes se apóiam a fim de buscar estabilidade política, social, jurídica ou civil.

Por outro lado, a bibliografia especializada insiste na importância com que as instituições constrangem os indivíduos cerceando seu comportamento. Segundo Goodin (1996), o neo-institucionalismo veio para dar conta justamente deste campo "inacabado" até então da ciência política. O objeto de estudo passa a ser não a organização da instituição em si, mas sim o modo como instituições moldam atitudes e criam estruturas desiguais no interior das mesmas. Porém, nesta mesma linha, o autor admite que as coações criam diferentes recursos de poder entre grupos e indivíduos.

Seguindo ainda a mesma linha, entendemos que instituições sugerem o seguinte:

Nós podemos, por exemplo, querer apenas estipular que uma instituição é necessariamente um fenômeno social. Indivíduos não são eles mesmos instituições, mesmo sabendo que estas 'estabelecem, valorizam e regulam' seus padrões de comportamento" (GOODIN, 1996, p. 20).

Esta denotação simples nos permite analisar as instituições por seu aparato externo e não pelo prisma categórico do neo-institucionalismo. Queremos poder analisar o design das instituições no sentido que o design das mesmas seja: a criação de formas acionáveis para promover inputs valorativos num determinado contexto. Assim entendemos a forma com que podemos utilizar o arcabouço teórico do institucionalismo para fins de análise da constituinte de 88. 
“[...] a Constituição de 1988 foi também impregnada pelo corporativismo da política brasileira. Constituiu-se a partir de um compromisso entre os setores da sociedade e do Estado que detinham poder naquele momento. Porém, ao invés de um compromisso em torno de regras fundamentais sobre os parâmetros sob os quais se deveria desenvolver o sistema político, deu-se um compromisso maximizador, no qual cada setor organizado da sociedade, através de um largo processo de barganha, alcançou a constitucionalização de interesses e demandas substantivas. Assim, ao lado de uma atualizadíssima carta de direitos e de uma ambígua distribuição vertical e horizontal de poderes, o legislador de 1988 constitucionalizou diversos temas que não pertenciam tradicionalmente aos corpos constitucionais, mesmo que se tenha em mente constituições de Estados sociais”. (VIEIRA, 1997).

Vieira bem coloca de que forma a constituinte de 88 serviu não só para moldar comportamentos internos, mas como instituição capaz de absorver demandas em sua organização. Este tópico será relembrado na análise do processo logo abaixo.

Porém, como se vê na citação, a distribuição de poderes, o arranjo com que a constituinte se fez, limitou sua atuação e fechou em si mesma limites que a caracterizam como instituição. As preferências adaptáveis dos atores (argumento de Elster, 1993) têm um ponto de tensionamento em que a democracia pode ser questionada. Ou seja, a tolerância sobre a inflexão de determinados valores constituintes chega a um ponto em que o limite entre processo e regime não podem avançar juntos. É aqui, no fechamento de limites, no procedimento padronizado, na defesa de interesses, nos recursos de poder, que as constituintes fecham-se. Por conta disto a relevância do objeto, por entender que a constituinte de 1988 no Brasil, permite uma abordagem não só sobre instituições políticas. Mas sim sobre instituições políticas na democracia (SUNSTEIN, 1993).

\section{A CONSTITUINTE BRASILEIRA DE 1988: INSTITUIÇÃO OU ORGANIZAÇÃO DE CONFLITOS?}

Não é preciso retomar aqui todo o arauto histórico e ideológico que deu início ao processo de formação da constituinte de 88. Personificados na figura de Ulysses Guimarães, os anseios por democracia, igualdade, queda do regime, estabilidade e manutenção destes todos foram organizados em torno do processo de feitura da nova carta constitucional. Ora, isso poderá ser analisado a partir de muitos prismas diferentes.

Jornalistas escreveram (e ainda escrevem) milhões de páginas ora bradando os louros de uma democracia consolidada por um escopo formal e jurídico, ora de um sistema jurídico-político que necessita de mudanças urgentes, ou o Brasil terá sua morte democrática decretada. Historiadores não se cansam em reescrever os atos das 
constituintes, dando mais peso à conjuntura, ou à história, ou aos indivíduos. Economistas não se cansam de se pronunciarem futurólogos do passado, prevendo hoje conseqüências de atos que foram cometidos durante os meses do funcionamento das comissões na ANC (Assembléia Nacional Constituinte). Ainda, cientistas políticos fizeram who is who, analisaram comissões, lideranças, partidos, decisões, poder e regras. Porém ninguém ainda tentou responder o quão institucionalizada, no sentido forte, está a idéia de constituinte no Brasil.

Partindo, então, do esboço teórico acima colocado, abordarei ponto a ponto e, a partir de literatura política sobre a constituinte, especialmente Pilatti (2006), tentaremos ver em que medida a constituinte brasileira de 1988 está mais ou menos desviante dos conceitos de instituição elaborados. Isto pode soar, num primeiro momento, um projeto ou uma idéia normativa. Porém, é disso que vivemos aqui, tentando abstrair realidades e transformá-las em preceitos analíticos, ou seja, conceitos teóricos.

O objetivo central é colocar a ANC de 87-88 nos seguintes parâmetros: saber se esta criava regulação entre membros com interesses ou características em comum; ii) aplicava tal regulação; iii) julgava a aplicação (ou não) da regulamentação e; iv) punia devidamente os descumpridores da regulação. Este é o primeiro passo. Vamos a ele.

O primeiro ponto é saber se a constituinte de 1988 surgiu com a busca por interesses comuns ou de grupos sociais relevantes que buscavam objetivos comungados. Esses interesses poderiam ser de qualquer forma, mas aqui o interesse comum dos membros que compunham a constituinte de 88 eram basicamente dois complementares entre si: a) o fim do regime autoritário (ou da ditabranda, nos termos colocados por O'Donnell e Schimitter na década de 80 para estudar regimes de transição) e; b) o desejo pela implantação do regime democrático no Brasil. A citação abaixo joga luz sobre estes dois pontos:

“[...] a Assembléia Nacional Constituinte de 1987-1988 (ANC) foi palco de grandes conflitos de interesse e opinião que haviam permanecido latentes, irresolutos ou agravados, durante os anos de repressão. Tais conflitos ensejaram mobilizações de intensidade e extensão inéditas na história das Constituintes brasileiras. Entre $1^{\circ}$ de fevereiro de 1987 e 5 de outubro de 1988, o edifício do Congresso Nacional, em Brasília, transformou-se em ponto de afluência de múltiplos setores organizados da sociedade brasileira.1 Ali aconteceu um processo decisório caracterizado pelo dissenso, pela intensa e permanente mobilização de atores coletivos internos e externos, por votações altamente polarizadoras e, ao mesmo tempo - sobretudo em sua fase final -, por uma atividade igualmente intensa e incessante de busca de acordos entre as lideranças[...]" (PILATTI, 2006, p. 01). 
Como podemos observar, o interesse comum entre as lideranças e entre os que estavam no interior da ANC era um fator a ser considerado. Mesmo sabendo das disputas que existiam entre os indivíduos, coletivos ou não, não podemos desconsiderar esse aspecto fundamental que dá um passo adiante no cumprimento de qualificar a ANC de 88 como uma instituição stricto senso.

Pilatti ainda lembra que o extraordinário grau de participação extraparlamentar foi algo antes nunca visto. Em nota de rodapé, lembra que os jornalistas da época tinham na ANC a esperança em trazer para o interior do Estado, membros que se encontravam fora dele. Ou seja, a democracia pairava como um valor reinante na ANC, dentro e fora. Reforçada então a tese de que interesses comuns uniam atores em prol da realização de um objetivo, o reestabelecimento da democracia e a blindagem que não permitisse o retorno de outras aventuras autoritárias. A citação abaixo ilustra:

"[...] a Constituinte marque um ponto de inflexão que separa o Brasil do autoritarismo do Brasil democratizado, expandindo os direitos da cidadania nos campos jurídico, econômico e social, redefinido as relações entre Legislativo, Executivo e Judiciário[...]” .) COELHO, 1999, p. 8).

O segundo ponto, como estabelecemos, é saber se a constituinte criou medidas que regulavam o comportamento dos atores - legisladores e expectadores. Seria imprudente e pedestre dizer que somente um contexto formal de regras fez com que esse ponto fosse pacífico pelos analistas e por mim. O fato de que regras existem no papel pouco diz sobre o real comportamento dos envolvidos na ANC. Porém, há um resíduo que não podemos deixar de notar quanto a este aspecto. São as comissões temáticas da ANC. Vale notar que outros arranjos poderiam se formar que não as comissões temáticas.

Talvez aqui resida o peso da história, mas como dissemos, as instituições não estão livres deste fardo. Exemplo disso é que a constituinte de 1937, convocada pelo então presidente Getúlio Dornelles Vargas, realizava seus trabalhos com duas frentes. A primeira eram comissões formadas por partidos de expressão e por frentes partidárias que ligavam-se em torno de um interesse ou ideal. A segunda era uma frente classista, que denotou ao governo Vargas um forte apelo popular durante a redação final da carta (MARTINS, 1999).

Porém a forte presença de comissões temáticas revela um traço importante para que coloquemos mais um pé da ANC de 88 dentro de nosso modelo de instituição. A formação de comissões temáticas nos mostra que havia uma preocupação em regular o conflito, em criar um desenho institucional que atendesse interesses diversos, 
independente de tonalidades partidárias (não estou afirmando que estas não existiam, mas formalmente as comissões poderiam abrigar atores de qualquer partido).

Ainda vemos que Coelho (1999) coloca a importância dos partidos durante a constituinte de 1988. Porém, os aspectos que o autor analisa levam em conta a coerência e a coesão dos partidos durante o processo decisório. Isso não está posto nos eixos organizacionais que desejamos aqui. Ou seja, por mais que reconheçamos a importância de partidos, esta observação ficará para um ponto à frente e não como critério que define a regulação da constituinte.

Na verdade, são nas comissões temáticas que abrigaram a frente de luta que ocorreu durante a ANC. Foram elas que regularam o conflito, que debateram os temas e que deliberaram sobre os interesses. Além disso, é claro, são elas quem dão o limite à constituinte. Isso, como lembra North (1990), é uma das principais características para classificar um corpo organizado como instituição.

A simples observação do texto de Pilatti (2006) mostra o grande papel das comissões temáticas. É nela que o autor concentra todos os seus esforços descritivos e analíticos. A devida importância é dada para esse pequeno cosmo organizativo. O impacto da organização nos procedimentos formais e informais de estratégia legislativa dos atores reflete duas coisas: i) a importância em se ter comissões temáticas que davam espaço para a formação de procedimentos legislativos padrão, como coalizões, frentes ideológicas, e a clássica divisão entre conservadores e progressistas e; ii) a forma com que diversos assuntos de interesse nacional foram alocados em suas devidas comissões, passando por inclusive, pelo sistema político que o Brasil adotaria.

Avistando o terceiro ponto da proposta, é possível ver na constituinte de 87-88 elementos que eram capazes de julgar descumprimentos de normas? Olhando esta por um ponto de vista mais geral podemos responder que não. Porém, se atentarmos ao ponto que Susnstein (1993) levanta, talvez possamos achar o elemento capaz de julgar comportamentos desviantes.

O ponto de Sunstein é que as instituições políticas permitem a existência ou a coexistência de outras instituições no seu interior. Isso pode ser visto essencialmente em dois elementos, o voto e os partidos políticos. Será então que estes dois elementos seriam capazes de julgar os comportamentos desviantes?

Nesse sentido nossa resposta é positiva. Porém, são apenas derivações extraídas da literatura. Este autor não realizou um trabalho de pesquisa empírica que desse conta de atribuir aos partidos e ao voto características ponderativas acerca dos comportamentos desviantes. A partir de Coelho (1999) e Pilatti (2006) observamos que os partidos eram atores relevantes. Vimos que estes partidos tinham papel preponderante no aspecto decisório, pois eram eles que formavam a agenda da 
constituinte. Por último, Coelho afirma que durante a ANC de 88, os partidos comportaram-se de forma coesa e coerente ${ }^{2}$.

\begin{abstract}
“[...] a percepção generalizada de que partidos brasileiros são menos coesos que os partidos existentes nas democracias consolidadas do Ocidente e que, por isso, sua força na esfera parlamentar seria aqui menos do que naqueles países, isso não invalidará o que aqui se sustenta: Que durante a Assembléia Nacional Constituinte os partidos políticos foram suficientemente coesos para, nos momentos decisivos, terem sido eles, e não blocos partidários como o Centrão, Frente Evangélica ou Bancada Ruralista, os eixos da articulação das maiorias parlamentares que aprovaram os diversos pontos do texto constitucional” (COELHO, 1999, p. 9).
\end{abstract}

Isso por outro lado, não nos autoriza a dizer que o comportamento coeso dos partidos era ao mesmo tempo coerente. Para isso Pilatti sustenta o seguinte: "a atuação dos integrantes das bancadas dos partidos de esquerda caracterizou-se por graus muito elevados de coesão e disciplina partidária” (2006, p. 13). Isso revela, o fator disciplina, que a coesão dos partidos era também em torno de temas e decisões tomadas por líderes de partido. Ou seja, a hipótese da coerência encontra também respaldo.

Chegamos então ao ponto de inflexão teórica e derivação analítica que anunciei. A partir do exame de dois autores, Coelho e Pilatti, saber em que medida os partidos tinham a capacidade de julgar seus membros é uma tarefa que parece sofrer de um leg interpretativo severo. Porém, tomemos o movimento inverso. Suponhamos que os partidos não tivessem nem coesão, nem tampouco coerência. Ou ainda que a disciplina não fosse um aspecto considerado por nenhum dos especialistas da ANC de 87-88. O que poderíamos ser levados a pensar é que não havia durante a ANC partidos capazes de coagir seus membros em torno de posições e/ou interesses.

Partindo do suposto de Coelho, 1999, de que a força partidária era grande nas deliberações e que os partidos eram, mais do que as coalizões de interesses, lideranças, valores, ou símbolos, os principais atores do processo decisório, pensamos que estas instituições são os rule-players da ANC. Assim sendo, podemos considerar que o eixo teórico julgar, é realizado senão pelos partidos políticos.

Complementariamente a este raciocínio a característica de aplicação, ou seja, da penalização pelo julgamento é feita simultaneamente e complementariamente pelos partidos políticos. Se supusermos que os partidos são passíveis de julgar o que é relevante, ou seja, manter a coerência, supõe também que a coesão está sinalizada de

\footnotetext{
${ }^{2} \mathrm{O}$ autor entende aqui que coeso refere-se ao fato de que os partidos comportaram-se de forma semelhante aos membros pares; coerente, não em sentido similar nem oposto, é entendido como a possibilidade com que os partidos têm em manter seu comportamento em sintonia com a ideologia e com a distribuição de poder nos mesmos.
} 
forma a subjetivar a penalização. Poderíamos citar aqui a infinidade de trabalhos recentes da ciência política brasileira que auferem às legendas políticas o controle sobre representação e sobre processo decisório. Mas entendemos que o friso dado por Coelho seja suficiente para a corroboração de nossa tese.

O segundo passo para ser estabelecido, era saber em que medida a constituinte de 88 encaixava-se nos aspectos de uma instituição propriamente política. Saber se esta desfrutava de duas condições: i.1) legitimidade e; i.2) mecanismo de sobrevivência.

O que cerca a legitimidade no caso exposto é exposto nos moldes de Weber, que considera este fenômeno como a crença num regime, através muito mais da adesão do que da coação. Ao que nos parece, os mecanismos de legitimidade estão intimamente ligados aos mecanismos de sobrevivência da instituição. Não é possível esperar que um conviva sem o outro, e não tampouco pensar qual dos dois regula o outro.

A legitimidade da constituinte funda-se em dois princípios: na representatividade, ou seja, no fato de que a ANC foi formada por deputados e senadores que foram eleitos. O voto aqui denota não somente legitimidade por conta da legitimidade-racional, mas também por conta da legitimidade-carismática. Isso representa dois pontos de um mesmo alicerce, colocando a ANC como capacitor de conhecimento para deliberações e de crença, a ação afetiva, de que esta assembléia seria capaz de fazer e restabelecer a democracia. Nossa tese vai ao encontro das conclusões de Souza e Lamounier (1989), onde supomos que a legitimidade da Constituinte estava alterada pela redistribuição de recursos de poder promovida pela ANC. Ela foi responsável por introduzir elementos de representatividade e estruturação de poder que antes não haviam sido presenciados na história do país. Segundo os autores:

\footnotetext{
"Obviamente, não estamos afirmando que a estrutura do poder fica alterada imediatamente por causa disto (por conta da redistribuição de poder que a carta supostamente promoveu em seu texto final). Afirmamos, sim, que mudanças nos critérios de legitimidade subjacentes a uma série de ações políticas, administrativas, judiciais e outras, abrem caminho para a futura transformação das relações de poder. Vista sob esse ângulo, a nova Constituição pode ser de fato considerada democrática”. (p. 101).
}

Ou seja, não supomos que a ANC distribui o poder e por conta disso é dotada de legitimidade. Mas pela forma com que foi conduzido o seu teor e pelo efeito que esta pode gerar, acreditamos que o fator legitimidade não possa ser desconsiderado.

$\mathrm{O}$ último item refere-se ao fato de saber em que medida a ANC criou mecanismos capazes de gerar sua própria sobrevivência. Poderíamos supor que todos 
os membros da ANC queriam que a mesma não naufragasse. $O$ motivo pode ser racional ou político. Se de um lado a permanência na ANC fazia com que os indivíduos projetassem duas carreiras e poderiam então abarcar mais votos, a sobrevivência seria racional. Por outro lado, podemos imaginar que a instituição estava marcada por divergências, como de fato estava ${ }^{3}$, e a luta política poderia motivar os indivíduos a permanecer desse modo. Porém imagino que a evidência deste mecanismo de sobrevivência esteja em outro lugar.

Primeiramente Panebianco (2005), sustenta que o objetivo final de toda organização é a sua sobrevivência. Possíveis e prováveis mudanças são parte do processo com que as instituições criam disposições duráveis que liguem à história às entranhas das mesmas.

A idéia contida aqui é de que as instituições acabam "agindo" de um modo inesperado por seus criadores. De que instituições dispõem de uma autonomia organizativa que vai além dos interesses dos atores, do que eles representam ou do que eles são. Nesse sentido vemos que:

\footnotetext{
"Uma série de decisões autônomas da própria Constituinte e da bancada majoritária, algumas de conseqüências inesperadas, outras resultantes da incorporação de costumes consagrados na política parlamentar ordinária, outras, ainda, creditáveis ao acaso, precondicionaram as possibilidades de incorporação, à Constituição aprovada, de inúmeros conteúdos típicos da agenda progressista”. (PILATTI, 2006, p. 312).
}

Ou seja, o fato de existir na criação da ANC um bloco no poder conservador e dotado de recursos importantes para a aprovação de matérias, parece que regras institucionais permitiram que a ala progressista tivesse muito a comemorar. Em minha percepção, isso se deve a dois fatores: i) o arranjo institucional e ii) o momento político. Esses dois fatores não são desligados entre si.

Se o arranjo institucional, com alta dose de costumes legislativos, comissões temáticas e presença de clivagem ideológica permitiu que a instituição ${ }^{4}$ criasse mecanismos que a fizeram permanecer não só durante os meses de sua atividade, mas até os dias de hoje, o momento político não poderia ser mais propício para a introdução de temas referentes ao sistema de governo, ao arranjo eleitoral e à tolerância democrática. Isso esteve presente sempre nas comissões temáticas.

\footnotetext{
3 Cfe. Pilatti, 2006, em especial Introdução.

4 Douglas North utilizaria o termo "instituição altamente institucionalizada".
} 


\section{CONSIDERAÇÕES FINAIS}

Como vemos no decorrer do artigo nossa intenção era cumprir parcialmente um escrutínio que contemplasse ou não um caso histórico específico em uma série de requisitos teóricos e supostamente normativos.

Entendemos que estes requisitos possuem de fato um tom regulatório, mas isso não é demérito quando estamos fazendo ciência, buscando adequar conceitos. Esse exercício de validade de mensuração poderá ser questionado em muitas frentes5.

A primeira delas é o modelo e os conceitos mobilizados. Não estamos interessados em avançar na discussão sobre o que são constituições. Estamos aqui realizando um exercício a partir de autores que qualificamos adequados para as exigências que nos propomos. Da mesma forma, poderia se perguntar sobre a validade das obras escolhidas que tratam a constituinte. Nesse sentido, lembramos que são escolhas que não exatamente referendam ou criticam nossos objetivos, mas que tem na Constituinte Brasileira de 1987-88 o tema central de suas análises.

Por outro lado, como podemos ver na última parte de nosso artigo, as condições para que a última constituinte brasileira seja de fato uma instituição política parecem ter sido cumpridas totalmente. De outra forma, a investigação sobre outros aspectos que formam as instituições poderiam ser desenhados, como a dependência do passado. Mas neste caso específico, descartamos tal objetivo.

Nossos critérios foram cumpridos totalmente, ora através da instituição da constituinte, ora com instituições que estavam abrigadas no interior da ANC. Lembramos é claro que os aspectos conjunturais devem ser considerados, bem como o papel das lideranças como Ulysses Guimarães, Mário Covas, Fernando Henrique Cardoso, José Sarney, entre outros. Mas, para nossos fins, estas variáveis parecem cumprir um papel analítico (frise-se o advérbio) menor do que o arranjo e as características aqui apresentadas.

Ainda, tratamos aqui da Constituinte de 1987-88 em suas linhas gerais. Muitos autores tratam ora de seu arranjo interno, ora dos blocos partidários, ora do processo decisório, etc. A intenção aqui foi apresentar características amplas que podem ser exprimidas em poucos pontos, mas que revelem ainda sim, aspectos importantes para a formação de conceitos e de arcabouço teórico.

Lembro que este foi um exercício que muitas vezes os cientistas políticos recusam-se em fazer por achá-lo menor ou menos importante. Talvez o resultado desta

\footnotetext{
5 Sobre isso, consultar: ADCOCK, Robert.; COLLIER, David. (2001). Measurament Validity: a shared standart for qualitative and quantitative research. In: The American Political Science Review. Vol. $95 ; \mathrm{n}^{0}$ 3. Pp. 529-546.
} 
análise não seja de fato o que mais importa. O que está de fato em evidência são os passos que o pesquisador toma, a construção dos conceitos, a mobilização de variáveis e o cotejo de fontes diferentes, como antes de qualquer outra coisa um aprendizado contínuo.

\section{REFERÊNCIAS BIBLIOGRÁFICAS}

ADCOCK, Robert.; COLLIER, David. Measurament Validity: a shared standart for qualitative and quantitative research. In: The American Political Science Review. Vol. 95; n 3. Pp. 529-546, 2001.

BRAGA, Sérgio S. Quem foi quem na Assembléia Constituinte de 1946. Brasília: Coordenação de Publicações da Câmara dos Deputados, 1998.

COELHO, Ricardo C. Partidos políticos, maiorias parlamentares e tomada de decisão na constituinte. Tese de doutorado. USP, 1999.

ELSTER, Jon. Constitutionalism and Democracy. New York: Cambridge University Press, 1993.

GOODIN, Robert. The Theory of Institucional Design. New York: Cambridge University Press, 1996.

MACEDO JR, Ronaldo Porto. Constituição, Soberania e Ditadura em Carl Shmitt. In: Dados - Revista de Ciências Sociais. Vol. 40, n. 1, 1997.

MARTINS, Vicente. Aspectos Jurídicos-educacionais da constituição de 1937. Mimeo: Universidade Federal de Santa Maria, 1999.

NORTH, Douglass C. Institutional Change and Economic Performance. New York: Cambridge University Press, 1990.

O’DONNELL, Guilhermo; SCHIMITTER, Philip; WHITEHEAD, Laurence. Transitions from authoritarian rule. London: Johns Hopkins University Press, 1986.

PANEBIANCO, Angelo. (2005). Modelos de Partido. Organização e poder nos partidos políticos. São Paulo: Martins Fontes, 2005.

PILATTI, A. Formas e Movimentos de um conflito Constitutivo: Progressistas, Conservadores e a definição da Ordem Econômica no Processo Constituinte 1987-88. Tese de doutorado. Iuperj, 2006.

A perspectiva institucionalista e a análise da dinâmica das decisões legislativas. In: Direito, Estado e Sociedade. Vol.9, n. 29., pp. 28-48, 2006.

ROTHSTEIN, Bo. (1998). Political Institutions: an Overview. In: GOODIN, Robert E.; KLINGEMANN, Hans-Dieter. A new handbook of Political Science. New York: Oxford University Press, 1998.

SKOCPOL, Theda. Bringing the State Back In: Strategies of Analysis in Current Research. In: EVANS, Peter B.; RUESCHEMEYER, Dietrich.; SKOCPOL, Theda. Bringing the State Back In. Cambridge: Cambridge University Press, 1985. 
SOUZA, Amaury de.; LAMOUNIER, Bolivar. A feitura da nova constituição: um reexame da cultura política brasileira. In: Planejamento e Políticas Públicas, n.2. Brasília: IPEA, 1989.

SUNSTEIN, Cass R. Constitutions and democracies: an epilogue. In: ELSTER, Jon. (1993). Constitutionalism and Democracy. New York: Cambridge University Press, 1993.

VIEIRA, Oscar Vilhena. A constituição como reserva de justiça. In: Revista Lua Nova. No. 42, 1997.

WEBER, Max. Ensaios de Sociologia. Rio de Janeiro: Ed. LTD, 1997. 